\title{
Factors associated with multidisciplinary case conference outcomes in children admitted to a regional hospital in Hong Kong with suspected child abuse: a retrospective case series with internal comparison
}

\author{
WC Lo, Genevieve PG Fung, Patrick CH Cheung *
}

\section{A B S T R A C T}

Introduction: In all cases of suspected child abuse, accurate risk assessment is vital to guide further management. This study examined the relationship between risk factors in a risk assessment matrix and child abuse case conference outcomes.

Methods: Records of all children hospitalised at United Christian Hospital in Hong Kong for suspected child abuse from January 2012 to December 2014 were reviewed. Outcomes of the hospital abuse work-up as concluded in the MultiDisciplinary Case Conference were categorised as 'established', 'high risk', or 'not established'. All cases of 'established' and 'high risk' were included in the positive case conference outcome group and all cases of 'not established' formed the comparison group. On the other hand, using the Risk Assessment Matrix developed by the California State University, Fresno in 1990, each case was allotted a matrix score of low, intermediate, or high risk in each of 15 matrix domains, and an aggregate matrix score was derived. The effect of individual matrix domain on case conference outcome was analysed. Receiver
This article was published on $18 \mathrm{Apr}$ 2017 at www.hkmj.org. examine the relationship between case conference outcome and aggregate matrix score.

Results: In this study, 265 children suspected of being abused were included, with 198 in the positive case conference outcome group and 67 in the comparison group. Three matrix domains (severity and frequency of abuse, location of injuries, and strength of family support systems) were significantly associated with case conference outcome. An aggregate cut-off score of 23 yielded a sensitivity of $91.4 \%$ and specificity of $38.2 \%$ in relation to outcome of abuse categorisation.

Conclusions: Risk assessment should be performed when handling suspected child abuse cases. A high aggregate score should arouse suspicion in all disciplines managing child abuse cases.

\section{Hong Kong Med J 2017:23:454-61}

DOI: 10.12809/hkmj164960

WC Lo, MRCPCH, FHKAM (Paediatrics)

GPG Fung, MRCPCH, FHKAM (Paediatrics)

PCH Cheung *, FRCPCH, FHKAM (Paediatrics)

Department of Paediatrics and Adolescent Medicine, United Christian Hospital, Kwun Tong, Hong Kong

* Corresponding author: cheungchp@ha.org.hk

New knowledge added by this study

The Risk Assessment Matrix provides an objective measure of the risk of abuse and can effectively aid communication between professionals and guide junior colleagues in decision making.

- Using the Risk Assessment Matrix, an aggregate matrix score of $\geq 23$ serves to alert health care professionals to the degree of risk involved, and to gauge appropriate follow-up response.

Implications for clinical practice or policy

Professionals should perform risk assessment and document the results in a systematic manner.

- Results of risk assessment should be considered in Multi-Disciplinary Case Conference on Protection of Child with Suspected Abuse to guide decision making and formulation of a welfare plan.

- As this study used a risk assessment matrix from overseas, further studies should be performed to develop an assessment tool for local use.

\section{Introduction}

Child abuse is damaging to children's physical health, emotional health, learning, and development. ${ }^{1-3}$ From time to time, there are media reports of severe child abuse that has required admission to an intensive care unit or resulted in death. A recent recommendation in March 2016 by a coroner following an inquest into the death of a 5-year-old child was the need for a careful risk assessment when handling cases of suspected child abuse. ${ }^{4}$

In Hong Kong, approximately 1000 children are admitted to hospitals each year for suspected 
child abuse. The abuse may be physical, sexual, or psychological; involve neglect; or consist of multiple abuses. ${ }^{5}$ Management of these children calls for multidisciplinary involvement. A MultiDisciplinary Case Conference on Protection of Child with Suspected Abuse (MDCC) is recommended as stated in the Procedural Guide for Handling Child Abuse Cases of the Social Welfare Department of the Hong Kong Special Administrative Region (HKSAR) Government. ${ }^{6}$ Whether a case is abuse or not is concluded by the MDCC that involves doctors, nurses, psychologists, medical social workers, social workers from Social Welfare Department or nongovernmental organisations, school personnel, and the police.

The Procedural Guide ${ }^{6}$ is under review. New procedures introduced in its recent revision have been implemented since December 2015. In Chapter 11 of the MDCC, a new standing conference agenda item on risk assessment was introduced and mandated. Managing professionals are advised to perform risk assessment on abuse. This risk assessment is vital when considering the nature of child abuse and the care of the child and family. Several assessment instruments or models to assess harm have been reviewed. ${ }^{7,8}$ Each has its own strengths and weaknesses. The Risk Assessment Matrix (developed by the California State University, Fresno, in 1990') has been quoted in the Procedural Guide for Handling Child Abuse Cases of the Social Welfare Department, HKSAR Government. ${ }^{6}$ The Risk Assessment Matrix has not been previously systematically used in MDCC in Hong Kong. Since 2015, the Social Welfare Department of HKSAR Government has recommended that systematic risk assessment be performed in MDCC for all cases. This study was performed to examine the relationship between risk factors in the Risk Assessment Matrix and MDCC outcome.

\section{Methods}

United Christian Hospital is a tertiary referral hospital that serves a paediatric population of around 110000 in the Kwun Tong district in Hong Kong. ${ }^{10}$ Children with suspected child abuse are admitted to hospitals in Hong Kong for multidisciplinary management that includes work-ups by paediatrics, psychology, psychiatry, social work disciplines as well as community social work agencies, schools, and the police. An MDCC is held within 10 working days in which all involved disciplines participate to conclude the nature of abuse (case conference outcome) and the subsequent welfare plan for the child and family. This was a retrospective case series with internal comparison to investigate the risk factors and case conference outcome of children admitted with suspected abuse from January 2012 to December 2014. Ethics approval for the study was
香港一所分區醫院內懷疑受虐兒童的特性與 多專業個案會議結果相關的因素：一個具內部 比較的回顧性病例系列研究

\author{
盧慧芝、馮寶姿、張志雄
}

引言：對於所有懷疑虐兒個案，準確的風險評估對進一步跟進至為重 要。本研究探討虐兒危機評估模式得出的風險因素與保護懷疑受虐兒 童多專業個案會議結果之間的關係。

方法：研究對象為2012年1月至2014年12月期間於香港聯合醫院接受 住院治療的懷疑受虐兒童。回顧他們的紀錄, 並按多專業個案會議結 果分為 $「$ 確立」、「高風險」或 $「 未$ 未確立」三個類別。把 $「$ 確立」和 $\ulcorner$ 高風險」病例都包括在病例組中, 其餘「未確立」的則為對照組。 另外, 使用由加州州立大學於1990年創立的Risk Assessment Matrix中 15 個範疇模式為每個個案評分, 把每項範疇模式的分數分為高、中或 低風險, 再湊合成一個總分數。然後分析每個範疇模式對多專業個案 會議結果的影響。使用受試者工作特徵曲線分析多專業個案會議結果 與總分之間的關係。

結果：分析了共265名懷疑虐兒個案, 其中病例組有 198例, 對照組則 有67例。以下三項範疇模式與多專業個案會議結果顯著相關：虐兒的 嚴重性和頻率、受害者受傷位置, 以及家庭支持。總分數的截數值為 23 分時, 個案分類的敏感性為 $91.4 \%$, 特異性為 $38.2 \%$ 。

結論：處理懷疑虐兒個案時應進行風險評估。對於總分數偏高的個 案, 應通知各處理單位以提高他們的警覺。

obtained from the Kowloon Central/Kowloon East Clusters Research Ethics Committee of the Hospital Authority.

\section{Subjects}

All cases of suspected child abuse (coded per the ICD-9 system) within the study period were identified from discharge diagnosis using the Hospital Authority Clinical Data Analysis and Reporting System electronic database. The medical records, the MDCC investigation reports by various disciplines, and the MDCC meeting minutes were retrieved and retrospectively reviewed. Cases were categorised as 'established' (E), 'high risk' (HR), or 'not established' (NE) for child abuse, as determined in the MDCC. All E and HR cases were included in the positive case conference outcome group, and all $\mathrm{NE}$ cases were included in the comparison group. Cases with no MDCC were excluded from analysis.

In this study, the ratio of E+HR:NE cases was 198:67 (ie 3:1). Using this sample size, and assuming an odds ratio (OR) of $>2$ would be considered significant, the chance of detecting a significant difference at the $5 \%$ level was $65 \%$.

\section{Measures}

Baseline demographic data, type of abuse, abusers, and relevant risk factors were collected for all cases. The Risk Assessment Matrix (developed by the 
California State University, Fresno, in $1990^{\circ}$ ) adopted by the Social Welfare Department in their Procedural Guide for Handling Child Abuse Cases ${ }^{6}$ was used to associate risk factors with final categorisation. The full risk assessment form is shown in the Appendix. This assessment categorises risk factors for child abuse into 15 matrix domains to assess the child, parent/caretaker, and family situation. For each matrix domain, the level of risk is classified as 'low' (MLR), 'intermediate' (MIR), or 'high' (MHR). The matrix was discussed in detail among the authors before starting the study, and details of classification clarified. Classification was performed by one author only, thereby eliminating the possibility of inter-rater variability. Cases that were difficult to classify were discussed among authors and decisions were made by consensus. Association between risk categories in the matrix and final categorisation was reviewed by looking at the MIR + MHR category in relation to case conference outcomes. To further quantify the matrix, an empirical scoring system was devised, with 1 point for MLR, 2 points for MIR, and 3 points for MHR in each of the 15 matrix domains. For each assessed case, an aggregate score of 15 to 45 was possible.

\section{Statistical analysis}

Statistical analysis was performed using the Statistical Package for the Social Sciences (Windows version 23.0; IBM Corp, Armonk [NY], United States). Categorical data were compared using the Chi squared test or Fisher's exact test (for cells $<5$ ), and OR with 95\% confidence interval (CI) were calculated. Continuous variables were compared using the independent $t$ test, Mann-Whitney $U$ test, or one-way analysis of variance (for multiple groups). Multivariate logistic regression (stepwise strategy) was used to determine the effect of individual matrix domains on case conference outcome. The independent variables used in logistic regression analysis were the matrices that showed a significant association in the initial univariate analysis. To study the association between matrix scores and final categorisation, a receiver operating characteristic (ROC) curve was plotted with sensitivity and specificity calculations. A two-sided $P$ value of $\leq 0.05$ was considered significant.

It was hypothesised that (1) risk factors for child abuse are present in a higher proportion in the E/HR cases compared with the NE cases, and (2) the aggregate risk profile score is higher in the positive case conference outcome group than in the comparison group.

\section{Results}

We identified 272 cases during the study period. After review of diagnosis and case notes, seven cases were excluded. For all excluded cases, no MDCC was held because they were judged to be inappropriate referrals for assessment of child abuse after initial careful assessment. Therefore, 265 cases were included in the study.

After multidisciplinary work-up, the case conference conclusion by MDCC showed that $46.0 \%$ $(122 / 265)$ of cases were categorised as E, $28.7 \%$ (76/265) as HR, and $25.3 \%(67 / 265)$ as NE. There were ultimately 198 cases in the positive case conference outcome group $(\mathrm{E}+\mathrm{HR})$ and 67 in the comparison group (NE). Physical abuse cases accounted for $70.9 \%(188 / 265)$, and the percentages of sexual abuse, neglect, and multiple abuse ( $\geq 2$ abuse categories) were $14.0 \%, 5.7 \%$, and $9.4 \%$, respectively. There were nine cases of psychological abuse ( $3 \mathrm{E}$ and $6 \mathrm{HR}$ ), but they were also confirmed to be associated with other types of abuse (eg 'physical + psychological' or 'neglect + psychological'). There were no cases of 'isolated psychological abuse' in this series (Table 1).

In most cases the abuser was identified as the mother $(45.5 \%, 90 / 198)$, followed by the father (27.3\%, 54/198), domestic helper $(4.0 \%, 8 / 198)$, parent's co-habitant $(2.0 \%, 4 / 198)$, grandfather $(1.5 \%, 3 / 198)$ or grandmother $(1.5 \%, 3 / 198)$, internet friend $(1.5 \%, 3 / 198)$, or stepfather $(1.0 \%, 2 / 198)$ or stepmother $(1.0 \%, 2 / 198)$. In $4.5 \%$ of cases, multiple abusers were identified, and in $5.1 \%$, the abuser could not be identified. Other abusers accounted for $5.1 \%$ and included tutorial class teachers, mother's friends, classmate or hostel peer, siblings, boyfriend, godmother, and other relatives.

Comparison of baseline demographic data showed no significant difference in gender, ethnicity, or mean age at presentation among the E, HR, and NE groups (Table 1). When the nature of abuse was compared, there was a higher percentage of physical abuse in the E and HR groups, but no significant difference in the percentage of psychological, multiple abuse, or neglect between groups. A significant difference was identified for sexual abuse, however, with the highest percentage in the NE group $(10.7 \%$ vs $9.2 \%$ vs $25.4 \% ; \mathrm{P}=0.007)$. Several features were observed in this subgroup of sexual abuse as follows. Multidisciplinary investigations and physical examination were frequently not revealing. Children were often young and thus unable to speak with non-specific vulval or perineal redness or symptomatic vulvovaginitis. Child custody disputes, maternal emotional problems, or a child being cared for by multiple individuals were common features.

Univariate analysis for the MIR + MHR categories in each matrix domain showed significant correlation between MIR + MHR in the positive case conference outcome group $(E+H R)$ for nine matrix domains, including Matrix 2, 3, 4, 5, 8, 9, 10, 11, and 14 (Table 2).

Logistic regression for these nine matrix 
TABLE I. Demographic data and nature of abuse of the three categorised groups

\begin{tabular}{|c|c|c|c|c|}
\hline Variable & Established (E) [n=122] & High risk (HR) [n=76] & Not established (NE) [n=67] & $P$ value \\
\hline Male gender & $61(50.0 \%)$ & $43(56.6 \%)$ & $28(41.8 \%)$ & 0.21 \\
\hline Chinese ethnicity & $120(98.4 \%)$ & $75(98.7 \%)$ & $65(97.0 \%)$ & 0.73 \\
\hline Mean ( \pm standard deviation) age (years) & $8.1 \pm 4.1$ & $7.8 \pm 4.6$ & $6.7 \pm 0.5$ & 0.10 \\
\hline \multicolumn{5}{|l|}{ Nature of abuse } \\
\hline Physical & $87(71.3 \%)$ & $60(78.9 \%)$ & $41(61.2 \%)$ & 0.041 \\
\hline Sexual & $13(10.7 \%)$ & $7(9.2 \%)$ & $17(25.4 \%)$ & 0.007 \\
\hline Neglect & $9(7.4 \%)$ & $3(3.9 \%)$ & $3(4.5 \%)$ & 0.06 \\
\hline Psychological & \multicolumn{4}{|c|}{ All psychological abuse cases were part of 'multiple abuse' in this series } \\
\hline \multirow[t]{2}{*}{ Multiple } & $13(10.7 \%)$ & $6(7.9 \%)$ & $6(9.0 \%)$ & 0.802 \\
\hline & \multicolumn{2}{|c|}{ Suspected child abuse $(E+H R+N E)[n=265]$} & \multicolumn{2}{|c|}{ Child abuse outcome in MDCC (E+HR) [n=198] } \\
\hline Physical abuse & \multicolumn{2}{|c|}{$188(70.9 \%)$} & \multicolumn{2}{|l|}{$147(74.2 \%)$} \\
\hline Sexual abuse & \multicolumn{2}{|c|}{$37(14.0 \%)$} & \multicolumn{2}{|l|}{$20(10.1 \%)$} \\
\hline Neglect & \multicolumn{2}{|c|}{$15(5.7 \%)$} & \multicolumn{2}{|l|}{$12(6.1 \%)$} \\
\hline Psychological abuse & \multicolumn{2}{|c|}{$0(0 \%)$} & \multicolumn{2}{|l|}{$9(4.5 \%)^{\star}$} \\
\hline Multiple abuse & \multicolumn{2}{|c|}{25 (9.4\%) } & \multicolumn{2}{|l|}{19 (9.6\%) } \\
\hline
\end{tabular}

* All psychological abuse cases were part of 'multiple abuse' in this series

TABLE 2. Univariate analysis of the relationship between intermediate + high matrix scores in the Risk Assessment Matrix developed by the California State University in 1990 with the Multi-Disciplinary Case Conference on Protection of Child with Suspected Abuse (MDCC) case conference outcome

\begin{tabular}{|c|c|c|c|c|}
\hline \multirow[t]{2}{*}{ Matrix domain* } & \multicolumn{2}{|c|}{ Case conference outcome determined by MDCC } & \multirow{2}{*}{$\begin{array}{l}\text { Odds ratio (95\% } \\
\text { confidence interval) }\end{array}$} & \multirow[t]{2}{*}{$P$ value } \\
\hline & Established / high risk & Not established & & \\
\hline Matrix 1 & 153/198 (77.3\%) & $59 / 67(88.1 \%)$ & $0.46(0.31-1.04)$ & 0.06 \\
\hline Matrix 2 & $182 / 198(91.9 \%)$ & $15 / 67(22.4 \%)$ & $3.28(1.52-7.08)$ & 0.002 \\
\hline Matrix 3 & $51 / 198(25.8 \%)$ & $9 / 67(13.4 \%)$ & $2.5(1.16-5.37)$ & 0.02 \\
\hline Matrix 4 & $110 / 198(55.6 \%)$ & $18 / 61(29.5 \%)$ & $3.40(1.85-6.25)$ & $<0.001$ \\
\hline Matrix 5 & $55 / 182(30.2 \%)$ & $9 / 60(15.0 \%)$ & $2.45(1.13-5.33)$ & 0.02 \\
\hline Matrix 6 & $108 / 198(54.5 \%)$ & $29 / 67(43.3 \%)$ & $1.57(0.90-2.75)$ & 0.11 \\
\hline Matrix 7 & $22 / 197(11.2 \%)$ & $2 / 67(3.0 \%)$ & $4.09(0.94-17.86)$ & 0.06 \\
\hline Matrix 8 & 174/198 (87.9\%) & $43 / 67(64.2 \%)$ & $4.05(2.09-7.80)$ & $<0.001$ \\
\hline Matrix 9 & 151/198 (76.3\%) & $38 / 67$ (56.7\%) & $2.45(1.36-4.39)$ & $<0.001$ \\
\hline Matrix 10 & 89/198 (44.9\%) & 19/67 (28.4\%) & $2.06(1.13-3.74)$ & 0.003 \\
\hline Matrix 11 & $132 / 198(66.7 \%)$ & 26/67 (38.8\%) & $3.15(1.78-5.59)$ & $<0.001$ \\
\hline Matrix 12 & 178/198 (89.9\%) & $57 / 67$ (85.1\%) & $1.56(0.69-3.53)$ & 0.28 \\
\hline Matrix 13 & 17/198 (8.6\%) & $1 / 67(1.5 \%)$ & $6.19(0.80-47.5)$ & 0.08 \\
\hline Matrix 14 & $167 / 198(84.3 \%)$ & 48/67 (71.6\%) & $2.13(1.11-41.1)$ & 0.023 \\
\hline Matrix 15 & $17 / 198(8.6 \%)$ & $4 / 67(6.0 \%)$ & $1.48(0.48-4.56)$ & 0.49 \\
\hline
\end{tabular}

* Matrix I = Child's age, physical and mental abilities; Matrix 2 = Severity and / or frequency of suspected abuse, physical or sexual; Matrix $3=$ Severity and / or frequency of suspected neglect and recentness; Matrix $4=$ Location of injuries; Matrix $5=$ School problems; Matrix $6=$ Caretaker's physical, intellectual, or emotional abilities; Matrix 7 = Caretaker's level of cooperation; Matrix 8 = Caretaker's parenting skills and / or knowledge; Matrix 9 = Presence of a parent substitute in the home; Matrix 10 = History of abuse / neglect; Matrix II = Strength of family support systems; Matrix 12 = Perpetrator's access to child; Matrix $13=$ Environmental condition of the home; Matrix $14=$ Stresses / crises; Matrix $15=$ Substance abuse drug / alcohol 
TABLE 3. Logistic regression analysis of intermediate + high matrix scores with case conference outcome for matrices $2,3,4,5,8$, $9,10,11,14$

\begin{tabular}{lcc}
\hline Matrix domain & $\begin{array}{c}\text { Adjusted odds ratio (95\% } \\
\text { confidence interval) }\end{array}$ & P value \\
\hline $\begin{array}{l}\text { Matrix } 2 \\
\text { (Severity and / or frequency of suspected physical or sexual abuse) }\end{array}$ & $3.05(1.06-8.73)$ & 0.038 \\
\hline $\begin{array}{l}\text { Matrix } 3 \\
\text { (Severity and / or frequency of suspected neglect and recentness) }\end{array}$ & 2.45 (0.97-6.19) & 0.057 \\
\hline $\begin{array}{l}\text { Matrix } 4 \\
\text { (Location of injuries) }\end{array}$ & $2.96(1.45-6.04)$ & 0.03 \\
\hline $\begin{array}{l}\text { Matrix } 5 \\
\text { (School problems) }\end{array}$ & $1.77(0.74-4.23)$ & 0.19 \\
\hline $\begin{array}{l}\text { Matrix } 8 \\
\text { (Caretaker's parenting skills and / or knowledge) }\end{array}$ & $1.92(0.82-4.49)$ & 0.13 \\
\hline $\begin{array}{l}\text { Matrix } 9 \\
\text { (Presence of a parent substitute in the home) }\end{array}$ & $1.66(0.80-1.45)$ & 0.17 \\
\hline $\begin{array}{l}\text { Matrix } 10 \\
\text { (History of abuse / neglect) }\end{array}$ & $1.71(0.85-3.42)$ & 0.13 \\
\hline $\begin{array}{l}\text { Matrix } 11 \\
\text { (Strength of family support systems) }\end{array}$ & $2.28(1.11-4.68)$ & 0.025 \\
\hline $\begin{array}{l}\text { Matrix } 14 \\
\text { (Stresses / crises) }\end{array}$ & $0.81(0.34-1.94)$ & 0.64 \\
\hline
\end{tabular}

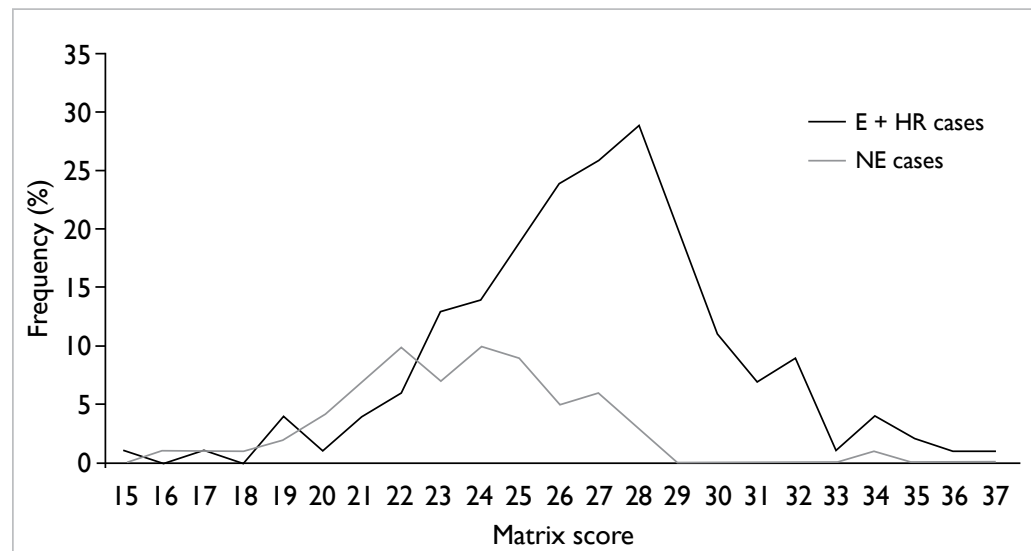

FIG I. Aggregate matrix scores for child abuse cases of 'established' (E) + 'high risk' $(\mathrm{HR})$ versus 'not established' (NE)

The mean ( \pm standard deviation) aggregate matrix score was $26.90 \pm 3.57$ for the $E+$ HR group, and $23.46 \pm 2.98$ for the NE group $(\mathrm{P}<0.005)$ two groups with a higher mean score in the positive case conference outcome group $(26.90 \pm 3.57$ vs $23.46 \pm 2.98 ; \mathrm{P}<0.005)$

To estimate the association of the matrix scores with the risk of child abuse, an ROC curve was plotted using aggregate matrix score against $\mathrm{E}+\mathrm{HR}$ cases (Fig 2). The area under the ROC curve was 0.78 (95\% CI, 0.72-0.84), indicating good discrimination.

The sensitivity and specificity of different aggregate matrix scores are shown in Figure 2. For this study, a matrix score that yielded a high sensitivity was preferred, in order to avoid missing cases of abuse. A cut-off aggregate matrix score of 23 would yield a sensitivity of $91.4 \%$ and specificity of $38.2 \%$ in relation to $\mathrm{E}+\mathrm{HR}$; a mean aggregate matrix score of 24 would yield a sensitivity of $84.8 \%$ and specificity of $48.5 \%$.

\section{Discussion}

Risk assessment is a critical process by which to assess the level of risk to a child suspected of being abused. Instruments used in risk assessment organise factors systematically to help describe the safety of such a child. These factors include characteristics of the reported abuse, the child, the caretakers, the family, and the environment of the child.,8,11-13 Such assessment helps case analysis and decision making, and provides an important framework for case planning and subsequent service delivery.

Since December 2015, risk assessment in MDCC has been mandated in the Procedural Guide for Handling Child Abuse Cases of the Social Welfare Department, HKSAR Government. ${ }^{6}$ 
In this Procedural Guide, a risk assessment instrument (Risk Assessment Matrix developed by the California State University, Fresno, in 1990) was referred to and takes the form of a matrix that facilitates assessment by professionals of the level of risk for various abuse factors. This study examined the relationship between child abuse risk factors and MDCC outcome using this Risk Assessment Matrix.

There was no significant difference in demographic data among the three groups $(\mathrm{E}, \mathrm{HR}$, and NE; Table 1). A statistical difference in the presence of child sexual abuse was found between the positive case conference outcome group (E+HR) and the comparison group (NE), with a higher proportion of children in the comparison group affected. Future study to analyse characteristic features of the NE group would aid understanding of sexual abuse cases that present to hospitals in Hong Kong.

There was no 'isolated' psychological abuse in this series. All psychological abuses occurred with multiple abuses. Psychological abuse is easily missed as there is often no physical sign to arouse suspicion. All cases in this series came to light during the work-up for other forms of abuse. In 2015, there were only seven cases of psychological abuse among the 874 newly reported child abuse cases in Hong Kong. ${ }^{14}$ Psychological abuse is underdiagnosed in our locality and this calls for sensitivity among professionals when handling abuse cases.

On characteristics of abusers, parents, especially mothers, were the most prevalent abusers. This finding is consistent with previous studies. ${ }^{12,15-17}$ Certain parental characteristics have been identified as important risk factors for child abuse, for example, parental low mood, marital conflict precipitating emotional problems, parental low education or economic status, poor social support, and parenting stress due to handling a child's disruptive behaviour. ${ }^{12,15-18}$

Logistic regression analysis revealed three factors that were significant for established or high risk of child abuse (E or HR): (1) Matrix 2: severity and/or frequency of suspected physical or sexual abuse, (2) Matrix 4: location of injuries, and (3) Matrix 11: strength of family support systems (Table 3).

\section{Matrix 2: Severity and/or frequency of suspected physical or sexual abuse}

History of child abuse, and severity and frequency of abuse are known risk factors for recurrence of abuse. Child abuse victims may not experience abuse as a one-off event. Further, there was evidence of escalation in abuse severity in recurrent abuse victims. $^{19,20}$ Corporal punishment is commonly adopted by Chinese parents as a method of child discipline, and severe physical punishment

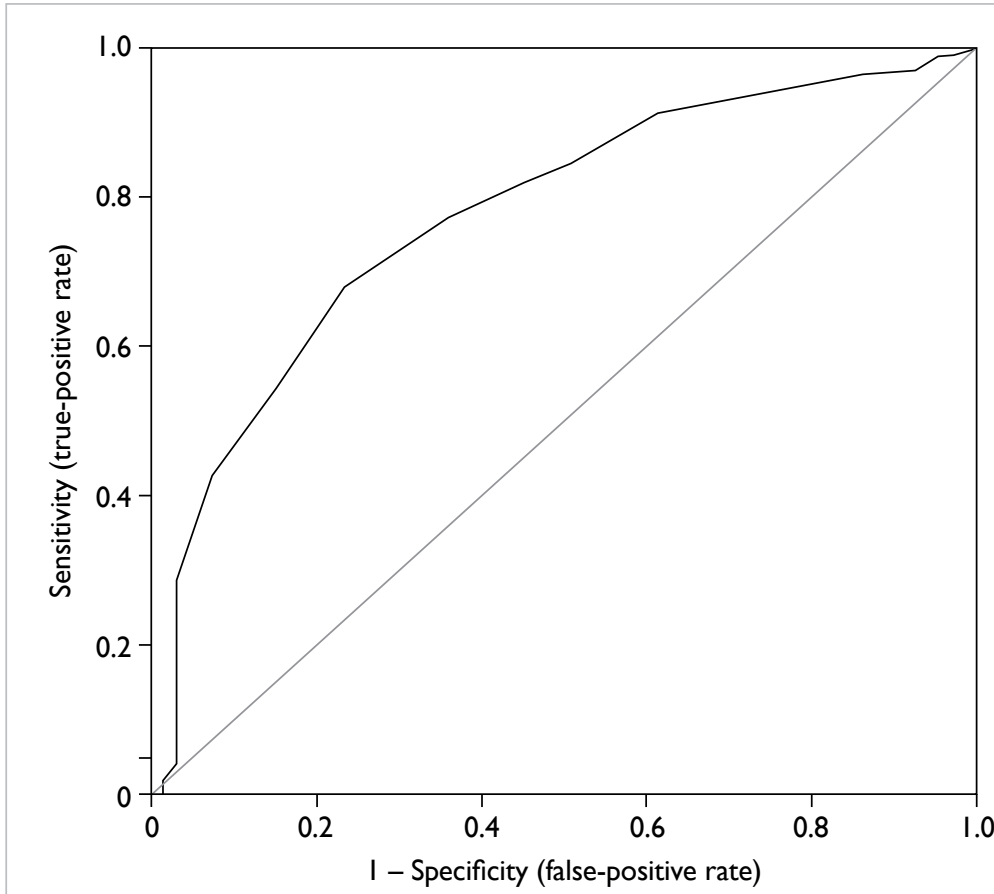

\begin{tabular}{|c|c|c|}
\hline Score & Sensitivity (\%) & Specificity (\%) \\
\hline 17 & 99.5 & 1 \\
\hline 18 & 99.0 & 3 \\
\hline 19 & 99.0 & 4 \\
\hline 20 & 97 & 7 \\
\hline 21 & 96.5 & 13.2 \\
\hline 22 & 94.4 & 24.5 \\
\hline 23 & 91.4 & 38.2 \\
\hline 24 & 84.8 & 48.5 \\
\hline 25 & 77.8 & 62.8 \\
\hline 26 & 68.2 & 76.5 \\
\hline 27 & 56.1 & 83.8 \\
\hline 28 & 42.9 & 92.6 \\
\hline 29 & 28.3 & 97.1 \\
\hline 30 & 18.2 & 97.1 \\
\hline 31 & 12.6 & 97.1 \\
\hline 32 & 9.1 & 97.1 \\
\hline
\end{tabular}

FIG 2. Receiver operating characteristic curve showing accuracy of matrix in relation to outcome

Diagonal segments are produced by ties

warranting medical attention or hospital admission has been reported in 3\% to $9 \%$ of children. ${ }^{15,18}$ Only $1 \%$ of abuse cases are reported and managed. ${ }^{15}$ Contributing factors for underreporting include cultural acceptance of corporal punishment, low public awareness, and lack of victim support during the disclosure process.

\section{Matrix 4: Location of injuries}

Head and neck injury was regarded as severe physical injury compared with injury to limbs and 
corporal body parts. ${ }^{18}$ A review of literature revealed that abusive bruises are found predominantly on the head and neck, especially on the ear, neck, and cheeks - all sites that are unlikely to be affected by accidental injury. Areas such as the forearms, upper limbs, and adjoining area of the trunk, or outside thigh may indicate 'defensive bruising' when the child tries to avoid being hit. ${ }^{21} \mathrm{Head}$ and neck injuries such as abusive head injury, contusions of the head or neck, are well known to cause deleterious effects, even mortality. ${ }^{22}$

\section{Matrix 11: Strength of family support systems}

Families with poor social support, social isolation, and geographical isolation are known to be at increased risk and severity of child abuse. ${ }^{16,17,19,22}$ Social isolation was more common among single parents or immigrants. ${ }^{15}$ Both a low level of real and perceived social support has been shown to be potential risks for child maltreatment. ${ }^{15-17}$ On the contrary, social support is a protective factor for child abuse. ${ }^{23}$ Perceived social support has been reported to moderate parents' own experience of abuse and the potential risk of abuse of their own children. ${ }^{16}$ Parental support can be offered by child care or foster care services, targeted support programmes for families at risk or young families with a newborn, parental counselling service, and extra support to vulnerable children with special needs. ${ }^{23}$

Six other matrix domains were significantly related with case conference outcome in univariate analysis but not in logistic regression analysis (Tables 2 and 3). They were Matrix 3, 5, 8, 9, 10 and 14. Another six risk factors were not statistically related to case conference outcome; these included Matrix 1, 6, 7, 12, 13, and 15. All risk factors in these domains have been shown in previous studies to be related to child abuse. ${ }^{11-13,15-17}$ Possible explanations for the absence of a significant relationship between risk factors in these 12 domains and case conference outcome in logistic regression analysis include an aggregate effect of risk factors that may not be significant on their own but factor co-occurrence is contributory. Other possible explanations include presence of mitigating factors such as a protective relative, a child already in supportive placement, the presence of legal enforcement or a child under a care order, or because of a small subgroup number within individual risk factors.

For the aggregate effect of risk factors, an ROC curve was plotted using aggregate matrix score against case conference outcome (Figs 1 and 2). As the Risk Assessment Matrix is used as a risk assessment tool for child abuse, it is vital that it detects most abuse cases. We chose a score that yields a high sensitivity and high positive predictive value whilst accepting a lower specificity. Using a score of 23 (sensitivity $91.4 \%$, positive predictive value 0.85 , specificity $38.2 \%$ ) or 24 (sensitivity $84.8 \%$, positive predictive value 0.8 , specificity $48.5 \%$ ) ensured that most child abuse cases were identified. The high sensitivity indicates that most cases of $\mathrm{E}$ and $\mathrm{HR}$ child abuse would be correctly identified in MDCC. A welfare plan could then be formulated to protect the child and help the family to prevent further abuse. The low specificity, however, meant that a relatively large number of 'non-child abuse' cases could be subject to unnecessary investigations, leading to an increased workload for all parties involved and stress to the family. Nonetheless, a highly sensitive cut-off is important to avoid a false-negative result and missing a genuine case of child abuse that may have serious or even fatal consequences.

In a recent death inquest, the importance of risk assessment was strongly emphasised by the coroner. ${ }^{4}$ The aggregate matrix score offers a reference to alert professionals in handling suspected child abuse cases. A matrix score of $>23$ calls for increased vigilance and careful planning, especially in situations such as making a decision about hospital discharge before MDCC. Further, because job placements of disciplines such as social work or legal enforcement are often rotation-based rather than long-term specialist-focused, where experience and professional judgement are important cumulative assets, a systematic risk assessment using objective scores serves as a practical tool and as a warning mechanism in abuse handling, especially for the less-experienced professionals.

This study has some limitations. In Hong Kong, reported cases of child abuse are only the tip of the iceberg. ${ }^{15}$ Subjects in this study were hospitalised children in a regional hospital setting, and results of this retrospective study cannot be generalised to the territory. The Fresno model has previously been considered a model with low validity and interrater reliability. ${ }^{7}$ As with other consensus-based risk assessment instruments, the rating of risks in the matrix domains will invariably involve a degree of subjectivity. ${ }^{7,8}$ This was minimised in this study by our further defining situations with objective measures. For example, for domain 10, intermediate risk was defined as a reported case but subsequently concluded as not an established child abuse case to be followed up by a school social worker or Integrated Family Services Centre. High risk was defined as a history of established child abuse in the past. For domain 14, insufficient income was defined as receipt of Comprehensive Social Security Assistance. Recent change in marital or relationship status was defined as parents in divorce proceedings, child in a custody dispute, or active marital discord causing emotional outbursts. It is hoped that with training and further refining of the matrix contents to fit the local culture, the inter-rater reliability and reproducibility of the Fresno tool can be improved. 
Nevertheless other risk assessment instruments can also be examined for local use.

The social structure and culture of a society keeps changing. Up-to-date studies are required to examine child abuse risk profiles. A prospective multicentre study is valuable for development of a local risk assessment tool. With the implementation of changes in the Procedural Guide for Handling Child Abuse Cases, ${ }^{6}$ a systematic risk assessment will facilitate investigative procedures and improve safeguarding of vulnerable children.

\section{Conclusions}

Three matrix risk factors in the Risk Assessment Matrix were significantly associated with child abuse-severity and / or frequency of suspected physical or sexual abuse (Matrix 2), location of injuries (Matrix 4), and strength of family support systems (Matrix 11). Further, other risk factors in the matrix, although not significant in logistic regression analysis, showed good association with child abuse case conference outcomes in univariate analysis. A risk assessment framework facilitates case analysis, and guides decision making and case planning such that appropriate service delivery is ensured. Using the devised scoring system of the referenced Risk Assessment Matrix, an aggregate matrix score of $\geq 23$ should arouse suspicion of all professionals when managing child abuse.

\section{Appendix}

Additional material related to this article can be found on the HKMJ website. Please go to <http:// www.hkmj.org>, and search for the article.

\section{Declaration}

All authors have disclosed no conflicts of interest.

\section{References}

1. Norman RE, Byambaa M, De R, Butchart A, Scott J, Vos $\mathrm{T}$. The long-term health consequences of child physical abuse, emotional abuse, and neglect: a systematic review and meta-analysis. PLoS Med 2012;9:e1001349.

2. Gilbert R, Widom CS, Browne K, Fergusson D, Webb E, Janson S. Burden and consequences of child maltreatment in high-income countries. Lancet 2009;373:68-81.

3. Felitti VJ, Anda RF, Nordenberg D, et al. Relationship of childhood abuse and household dysfunction to many of the leading causes of death in adults. The Adverse Childhood Experiences (ACE) study. Am J Prev Med 1998;14:245-58.

4. Siu J. Hong Kong government urged to amend guide on handling child abuse in coroner's case involving death of boy who probably ingested Ice. South China Morning Post 2016 Mar 16.

5. Clinical Data Analysis and Reporting System, Hong Kong Hospital Authority. Accessed 16 Nov 2016.

6. Social Welfare Department of the Hong Kong SAR Government. Procedural Guide for Handling Child Abuse
Cases 2015. Available from: http://www.swd.gov.hk/ en/index/site_pubsvc/page_family/sub_fcwprocedure/ id_1447/. Accessed 16 Nov 2016.

7. D’Andrade A, Austin MJ, Benton A. Risk and safety assessment in child welfare: instrument comparisons. J Evid Based Soc Work 2008;5:31-56.

8. Barlow J, Fisher JD, Jones D. Systematic review of models of analysing significant harm. Research report DFE-RR199. London: Department for Education; 2012.

9. California risk assessment curriculum for child welfare services, CSU Fresno, Child Welfare Training Project. Sponsored and funded by the California State Department of Social Service; 1990.

10. Census and Statistics Department. Population and household statistics analysed by District Council district. Hong Kong, Hong Kong SAR Government; 2016.

11. Milner JS. Assessing physical child abuse risk: the child abuse potential inventory. Clin Psychol Rev 1994;14:54783.

12. Begle AM, Dumas JE, Hanson RF. Predicting child abuse potential: an empirical investigation of two theoretical frameworks. J Clin Child Adolesc Psychol 2010;39:208-19.

13. Chan YC, Lam GL, Chun PK, So MT. Confirmatory factor analysis of the Child Abuse Potential Inventory: results based on a sample of Chinese mothers in Hong Kong. Child Abuse Negl 2006;30:1005-16.

14. Social Welfare Department. Child Protection Registry statistical report 2015. Hong Kong: Hong Kong SAR Government; 2015.

15. Study on child abuse and spouse battering. Report on findings of household survey. Hong Kong SAR: Department of Social Work and Social Administration, The University of Hong Kong; 2005.

16. Yoon AS. The role of social support in relation to parenting stress and risk of child maltreatment among Asian American immigrant parents [dissertation]. US: University of Pennsylvania; 2013.

17. Brown J, Cohen P, Johnson JG, Salzinger S. A longitudinal analysis of risk factors for child maltreatment: findings of a 17-year prospective study of officially recorded and self-reported child abuse and neglect. Child Abuse Negl 1998;22:1065-78.

18. Leung PW, Wong WC, Chen WQ, Tang CS. Prevalence and determinants of child maltreatment among high school students in Southern China: a large scale school based survey. Child Adolesc Psychiatry Ment Health 2008;2:27.

19. Thackeray J, Minneci PC, Cooper JN, Groner JI, Deans KJ. Predictors of increasing injury severity across suspected recurrent episodes of non-accidental trauma: a retrospective cohort study. BMC Pediatr 2016;16:8.

20. Deans KJ, Thackeray J, Groner JI, Cooper JN, Minneci PC. Risk factors for recurrent injuries in victims of suspected non-accidental trauma: a retrospective cohort study. BMC Pediatr 2014;14:217.

21. Maguire S. Which injuries may indicate child abuse? Arch Dis Child Educ Pract Ed 2010;95:170-7.

22. Kemp AM. Abusive head trauma: recognition and the essential investigation. Arch Dis Child Educ Pract Ed 2011;96:202-8.

23. Chan KL. Study on child-friendly families: Immunity from domestic violence. Hong Kong SAR: Department of Social Work and Social Administration, The University of Hong Kong; 2008. 